\title{
Ig Kappa Chain V-IV Region
}

National Cancer Institute

\section{Source}

National Cancer Institute. Ig Kappa Chain V-IV Region. NCI Thesaurus. Code C117121.

Ig kappa chain V-IV region (121 aa, 13 kDa) is encoded by the human IGKV4-1 gene.

This protein plays a role in antibody specificity. 